УДК 546.221:539.232:538.9

DOI: https://doi.org/10.17308/kcmf.2019.21/762

Поступила в редакцию 19.03.2019

Подписана в печать 15.05.2019

\title{
ОСАЖДЕНИЕ СЛОЕВ СУЛЬФИДОВ КАДМИЯ И СВИНЦА ИЗ ТИОСУЛЬФАТНО-ТИОМОЧЕВИННЫХ КОМПЛЕКСОВ И ИССЛЕДОВАНИЕ ИХ СВОЙСТВ
}

\author{
(c) 2019 В. Н. Семенов ${ }^{1}$, Т. В. Самофалова ${ }^{1} \rrbracket$, А. В. Наумов ${ }^{1}$, Н. М. Овечкина ${ }^{2}$ \\ ${ }^{1}$ Воронежский государственный университет \\ Университетская пл. 1, 394018 Воронеж, Российская Федерация \\ ${ }^{2}$ Воронежский государственный медицинский университет имени Н.Н. Бурденко \\ ул. Студенческая, 10, 394036 Воронеж, Российская Федерация
}

\begin{abstract}
Аннотация. Представлены результаты исследования пленок сульфидов кадмия и свинца, осажденных методом пиролиза аэрозоля из водных растворов тиомочевинно-тиосульфатных координационных соединений при температуре $400{ }^{\circ} \mathrm{C}$. Исследование ТТКС показало, что в водных растворах, содержащих нитрат кадмия, тиосульфат натрия и тиомочевину с разными молярными соотношениями компонентов, образуются координационные соединения $\left[\mathrm{Cd}\left(\mathrm{SCN}_{2} \mathrm{H}_{4}\right)_{2}\left(b_{i}-\mathrm{S}_{2} \mathrm{O}_{3}\right)\right]$, а в соответствующих по составу растворах нитрата свинца формируются комплексы $\left[\mathrm{Pb}\left(\mathrm{SCN}_{2} \mathrm{H}_{4}\right)\left(b i-\mathrm{S}_{2} \mathrm{O}_{3}\right)\left(\mathrm{H}_{2} \mathrm{O}\right)\right]$. Методом инфракрасной спектроскопии установлено, что при образовании смешанных ТТКС свинца, а также кадмия, осуществляется монодентатная координация тиомочевины к катиону металла через атом серы, а тиосульфат-ион координируется бидентатно через серу и кислород. С помощью рентгенофазового анализа установлено, что независимо от соотношения компонентов в исходном растворе пленки сульфида кадмия кристаллизуются в модификации вюртцита, а пленки сульфида свинца - в кубической структуре. Определена оптическая ширина запрещенной зоны синтезированных пленок, составляющая $2.4 \pm 0.01$ эВ для сульфида кадмия и $0.50-$ 0.56 эВ для сульфида свинца.
\end{abstract}

Ключевые слова: тиомочевинные координационные соединения, тиомочевинно-тиосульфатные координационные соединения, метод пиролиза аэрозоля, сульфид кадмия, сульфид свинца, пленки.

\section{ВВЕДЕНИЕ}

Координационные соединения солей кадмия и свинца с тиомочевиной и ее производными представляют значительный интерес ввиду возможности их практического использования как прекурсоров при получении пленок сульфидов металлов. Образование твердых фаз сульфидов может происходить путем термической деструкции тиомочевинных координационных соединений (ТКС) в процессе пиролиза аэрозоля их раствора [1, 2] либо при сгорании твердых образцов комплексов, содержащих анион-окислитель $\mathrm{NO}_{3}{ }^{-}$ [3]. Также возможно осаждение сульфидов металлов путем распада ТКС в водных растворах [4].

Ранее было изучено комплексообразование различных солей кадмия и свинца с тиомочевиной, а также термическое разложение образую-

$\triangle$ Самофалова Татьяна Владимировна, e-mail: TSamofalova@bk.ru щихся координационных соединений $[2,5,6]$. В работах $[7,8]$ были исследованы координационные соединения, образующиеся в водных растворах при взаимодействии нитрата свинца, тиосульфата натрия и тиомочевины. Авторами [7, 8] установлено, что в системе $\mathrm{Pb}\left(\mathrm{NO}_{3}\right)_{2}-\mathrm{Na}_{2} \mathrm{~S}_{2} \mathrm{O}_{3}-$ $\mathrm{SCN}_{2} \mathrm{H}_{4}-\mathrm{H}_{2} \mathrm{O}$ в зависимости от соотношения компонентов в исходном растворе формируются комплексы состава $\left[\mathrm{Pb}\left(b i-\mathrm{S}_{2} \mathrm{O}_{3}\right)\left(\mathrm{SCN}_{2} \mathrm{H}_{4}\right)\left(\mathrm{H}_{2} \mathrm{O}\right)\right]$ и $\left[\mathrm{Pb}\left(\right.\right.$ mono- $\left.\left.\mathrm{S}_{2} \mathrm{O}_{3}\right)\left(\mathrm{SCN}_{2} \mathrm{H}_{4}\right)_{2}\left(\mathrm{H}_{2} \mathrm{O}\right)\right]$. В первом из них тиосульфат-ион координируется бидентатно через атомы серы и кислорода, во втором - монодентатно. Тиомочевина во всех случаях координируется монодентатно через атом серы. При термолизе таких тиосульфатно-тиомочевинных координационных соединений (ТТКС) образуется сульфид свинца.

Цель данной работы - осаждение пленок сульфидов свинца и кадмия из тиосульфатно- 
тиомочевинных комплексов и изучение их кристаллической структуры и оптических свойств.

\section{ЭКСПЕРИМЕНТАЛЬНАЯ ЧАСТЬ}

Пленки сульфидов кадмия и свинца синтезировали методом пиролиза аэрозоля (ПА) водных растворов тиосульфатно-тиомочевинных координационных соединений, образующихся при взаимодействии нитрата соответствующего металла, тиомочевины и тиосульфата натрия, концентрация которого варьировалась. Использование нитрат-иона обусловлено тем, что он не входит во внутреннюю сферу образующегося комплекса [5]. Концентрация соли металла в распыляемом растворе составляла $0.5 \mathrm{~mol} / \mathrm{l}, \mathrm{KoH}-$ центрация тиомочевины - $1 \mathrm{~mol} / \mathrm{l}$, концентрация тиосульфата натрия варьировалась от 1 до $2.5 \mathrm{~mol} / \mathrm{l}$. Для получения TTКС в водном растворе использовали соли $\mathrm{Cd}\left(\mathrm{NO}_{3}\right)_{2} \cdot 4 \mathrm{H}_{2} \mathrm{O}, \mathrm{Pb}\left(\mathrm{NO}_{3}\right)_{2}$ и $\mathrm{Na}_{2} \mathrm{~S}_{2} \mathrm{O}_{3} \cdot 5 \mathrm{H}_{2} \mathrm{O}$ марки «х. ч.», а также тиомочевину $\mathrm{SCN}_{2} \mathrm{H}_{4}$ марки «ос. ч.».

В качестве подложек использовали кварцевые и ситалловые пластины, которые предварительно промывали в азотной кислоте и хромовой смеси, затем многократно в дистиллированной воде.

Растворы ТТКС распыляли при помощи пневматической форсунки на нагретую до $400{ }^{\circ} \mathrm{C}$ подложку, на которой в результате термодеструкции комплексов выделялся сульфид металла. Время напыления образца составляло 1-2 минуты.

Фазовый состав пленок исследовали методом рентгенофазового анализа (РФА) на дифрактометре ДРОН-3 (фильтрованное Ni излучение $\left.\mathrm{CuK} K_{\alpha}\right)$. Дифрактограммы записывали в интервале углов $2 \theta$ от $20^{\circ}$ до $80^{\circ}$. Для интерпретации полученных данных использовали базу данных [9].

Для изучения оптических свойств пленок снимали спектры пропускания в области края фундаментального поглощения. Спектры пропускания образцов $\mathrm{PbS}$ регистрировали на ИК Фурье-спектрометре Vertex 70 в диапазоне 2000$7000 \mathrm{~cm}^{-1}$. Спектры пропускания пленок CdS снимали на спектрометре Perkin Elmer в диапазоне 200-1000 nm, со спектральным разрешением $1 \mathrm{~nm}$. Измерения проводились при комнатной температуре. Оптическую ширину запрещенной зоны $E_{\mathrm{g}}$ исследуемых сульфидов определяли по краю собственного поглощения из спектральной зависимости $D=f(h v)(D-$ оптическая плотность) для прямых разрешенных переходов [10, 11].

Для выяснения механизма взаимодействия нитрата кадмия и свинца с тиомочевиной и ти- осульфат-ионами были сняты инфракрасные спектры комплексов. ИК спектроскопические исследования проводили методом нарушенного полного внутреннего отражения, спектры пропускания снимали на ИК Фурье-спектрометре Vertex 70 в диапазоне 500-4000 cm-1. Комплексы кадмия и свинца выделяли из рабочих растворов путем медленного испарения растворителя. Предварительно образцы готовили в виде порошка.

\section{РЕЗУЛЬТАТЫ И ИХ ОБСУЖДЕНИЕ}

Максимумы полос поглощения в ИК спектрах координационных соединений, полученных из водных растворов нитрата кадмия и свинца, тиосульфата натрия и тиомочевины с различным соотношением компонентов, представлены в табл. 1, 2.

При сравнении спектров свободной тиомочевины и комплексов видно, что частоты валентных колебаний $v_{\mathrm{NH}}$ и $\mathrm{v}_{\mathrm{CN}}$ координированной молекулы тиомочевины смещены в высокочастотную область, а частоты колебаний связи $v_{C S}-$ в низкочастотную область спектра относительно соответствующих колебаний свободной тиомочевины. Это позволяет утверждать, что координация тиомочевины к катиону металла осуществляется через атом серы, поскольку при переходе от свободной тиомочевины к координированной силовая постоянная связи $K_{\mathrm{CS}}$ несколько уменьшается, а силовые постоянные $K_{\mathrm{CN}}$ и $K_{\mathrm{NH}}$ - увеличиваются $[12,13]$. Аналогичные результаты были получены ранее при исследовании координационных соединений солей кадмия, цинка, свинца и других металлов с тиомочевиной $[2,5,6]$.

По данным $[14,15]$ наиболее достоверными для определения координации лиганда $\mathrm{S}_{2} \mathrm{O}_{3}^{2-}$ в тиосульфатных соединениях являются частоты валентных колебаний связи «сера-кислород»: $v_{a s(\mathrm{SO})}>1175 \mathrm{~cm}^{-1}$ (S-мостиковая координация); $1175-1130 \mathrm{~cm}^{-1}$ (S-координация); $1130 \mathrm{~cm}^{-1}$ (ионная связь); $v_{\text {as }}(\mathrm{SO})<1130 \mathrm{~cm}^{-1}$ (О-координация). Кроме того, на координацию тиосульфатиона через атом серы указывает смещение частоты $v_{s(\mathrm{so})}$ в область выше $1000 \mathrm{~cm}^{-1}$, а при координации через атом кислорода должно наблюдаться смещение в область ниже $1000 \mathrm{~cm}^{-1}$.

Присутствие в ИК спектрах ТТКС кадмия и свинца полос поглощения, отвечающих асимметричным колебаниям $v_{a s(\text { so) }}$ в области 1175$1130 \mathrm{~cm}^{-1}$ (табл. 1, 2), указывают на координацию тиосульфат-иона через атом серы, а частоты в области значений менее $1130 \mathrm{~cm}^{-1}$ - на координацию этого лиганда через атом кислорода. Кро- 
Табл. 1. Максимумы полос поглощения $\left(\mathrm{cm}^{-1}\right)$ ИК спектров координационных соединений, полученных из водных растворов $\mathrm{Cd}\left(\mathrm{NO}_{3}\right)_{2}-\mathrm{SCN}_{2} \mathrm{H}_{4}-\mathrm{Na}_{2} \mathrm{~S}_{2} \mathrm{O}_{3}$

[Table 1. Maximum absorption bands $\left(\mathrm{cm}^{-1}\right)$ of IR spectra of coordination compounds, prepared from aqueous solutions $\mathrm{Cd}\left(\mathrm{NO}_{3}\right)_{2}-\mathrm{SCN}_{2} \mathrm{H}_{4}-\mathrm{Na}_{2} \mathrm{~S}_{2} \mathrm{O}_{3}$ ]

\begin{tabular}{|c|c|c|c|c|c|}
\hline \multirow[t]{2}{*}{$\begin{array}{l}\text { Отнесение } \\
\text { [Assignment] }\end{array}$} & \multirow[t]{2}{*}{$\begin{array}{l}\mathrm{SCN}_{2} \mathrm{H}_{4} \\
{[12,13]}\end{array}$} & \multirow[t]{2}{*}{$\begin{array}{l}\mathrm{Na}_{2} \mathrm{~S}_{2} \mathrm{O}_{3} \\
{[14,15]}\end{array}$} & \multicolumn{3}{|c|}{$\begin{array}{c}\text { Молярное соотношение компонентов } \\
\mathrm{Cd}\left(\mathrm{NO}_{3}\right)_{2}-\mathrm{SCN}_{2} \mathrm{H}_{4}-\mathrm{Na}_{2} \mathrm{~S}_{2} \mathrm{O}_{3} \\
{\left[\text { Molar ratio of components } \mathrm{Cd}\left(\mathrm{NO}_{3}\right)_{2}-\mathrm{SCN}_{2} \mathrm{H}_{4}-\mathrm{Na}_{2} \mathrm{~S}_{2} \mathrm{O}_{3}\right]}\end{array}$} \\
\hline & & & $1: 2: 2$ & $1: 2: 3$ & $1: 2: 4$ \\
\hline$v_{\mathrm{NH}}$ & $\begin{array}{l}3380 \\
3275 \\
3190\end{array}$ & & 3317 & $\begin{array}{l}3342 \\
3200\end{array}$ & $\begin{array}{l}3390 \\
3307 \\
3205\end{array}$ \\
\hline$\delta_{\mathrm{HNH}}$ & 1611 & & 1633 & 1633 & $\begin{array}{l}1660 \\
1616\end{array}$ \\
\hline $\begin{array}{c}v_{\mathrm{CN}} \\
v_{\mathrm{HNC}}\end{array}$ & 1472 & & $\begin{array}{l}1550 \\
1412 \\
1348\end{array}$ & $\begin{array}{l}1550 \\
1410 \\
1346\end{array}$ & 1495 \\
\hline$v_{C S}$ & 1414 & & & & 1390 \\
\hline$v_{\mathrm{as}(\mathrm{SO})}$ & & $\begin{array}{l}1160 \\
1130\end{array}$ & 1162 & 1155 & 1163 \\
\hline $\mathrm{v}_{\mathrm{CN}}$ & 1086 & & 1115 & 1114 & 1110 \\
\hline$v_{\mathrm{s}(\mathrm{SO})}$ & & 1002 & 998 & 1002 & 997 \\
\hline$v_{\mathrm{CS}}$ & 732 & & & 705 & 703 \\
\hline$\delta_{\mathrm{s}(\mathrm{SO})}$ & & $\begin{array}{l}680 \\
668\end{array}$ & & & \\
\hline$\delta_{\mathrm{NCN}}$ & 634 & & & & $\begin{array}{l}636 \\
603\end{array}$ \\
\hline$\delta_{\mathrm{as}(\mathrm{SO})}$ & & $\begin{array}{l}555 \\
535\end{array}$ & & & 532 \\
\hline
\end{tabular}

Табл. 2. Максимумы полос поглощения $\left(\mathrm{cm}^{-1}\right)$ ИК спектров координационных соединений, полученных из водных растворов $\mathrm{Pb}\left(\mathrm{NO}_{3}\right)_{2}-\mathrm{SCN}_{2} \mathrm{H}_{4}-\mathrm{Na}_{2} \mathrm{~S}_{2} \mathrm{O}_{3}$

[Table 2. Maximum absorption bands $\left(\mathrm{cm}^{-1}\right)$ of IR spectra of coordination compounds, prepared from aqueous solutions $\mathrm{Pb}\left(\mathrm{NO}_{3}\right)_{2}-\mathrm{SCN}_{2} \mathrm{H}_{4}-\mathrm{Na}_{2} \mathrm{~S}_{2} \mathrm{O}_{3}$ ]

\begin{tabular}{|c|c|c|c|c|c|}
\hline \multirow[t]{2}{*}{$\begin{array}{l}\text { Отнесение } \\
\text { [Assignment] }\end{array}$} & \multirow[t]{2}{*}{$\begin{array}{l}\mathrm{SCN}_{2} \mathrm{H}_{4} \\
{[12,13]}\end{array}$} & \multirow[t]{2}{*}{$\begin{array}{l}\mathrm{Na}_{2} \mathrm{~S}_{2} \mathrm{O}_{3} \\
{[14,15]^{2}}\end{array}$} & \multicolumn{3}{|c|}{$\begin{array}{c}\text { Молярное соотношение компонентов } \\
\mathrm{Pb}\left(\mathrm{NO}_{3}\right)_{2}-\mathrm{SCN}_{2} \mathrm{H}_{4}-\mathrm{Na}_{2} \mathrm{~S}_{2} \mathrm{O}_{3} \\
\left.\text { [Molar ratio of components } \mathrm{Pb}\left(\mathrm{NO}_{3}\right)_{2}-\mathrm{SCN}_{2} \mathrm{H}_{4}-\mathrm{Na}_{2} \mathrm{~S}_{2} \mathrm{O}_{3}\right]\end{array}$} \\
\hline & & & $1: 2: 2$ & $1: 2: 3$ & $1: 2: 4$ \\
\hline$v_{\mathrm{OH}}$ & & & 3405 & 3447 & 3450 \\
\hline$v_{\mathrm{NH}}$ & $\begin{array}{l}3380 \\
3275 \\
3190\end{array}$ & & $\begin{array}{l}3382 \\
3292 \\
3207\end{array}$ & $\begin{array}{l}3382 \\
3293 \\
3210\end{array}$ & $\begin{array}{l}3383 \\
3292 \\
3210\end{array}$ \\
\hline $\begin{array}{c}\delta_{\mathrm{HNH}} \\
\delta_{\mathrm{OH}}\end{array}$ & 1611 & & 1625 & 1625 & 1626 \\
\hline$\delta_{\mathrm{HNX}}$ & & & 1530 & 1530 & 1530 \\
\hline $\begin{array}{l}v_{\mathrm{CN}} \\
v_{\mathrm{HNC}} \\
\end{array}$ & 1472 & & & & \\
\hline$v_{\mathrm{CS}}$ & 1414 & & 1409 & 1408 & 1409 \\
\hline$v_{a s(\mathrm{SO})}$ & & $\begin{array}{l}1140 \\
1116\end{array}$ & 1134 & 1134 & 1134 \\
\hline$v_{\mathrm{CN}}$ & 1086 & & & & \\
\hline$v_{s(\mathrm{SO})}$ & & 988 & 998 & 998 & 998 \\
\hline$v_{\mathrm{CS}}$ & 732 & & 703 & 705 & 703 \\
\hline$\delta_{s(\mathrm{SO})}$ & & $\begin{array}{l}645 \\
624\end{array}$ & 650 & 650 & 650 \\
\hline$\delta_{\mathrm{NCN}}$ & 634 & & & & \\
\hline$\delta_{a s(\mathrm{SO})}$ & & $\begin{array}{l}541 \\
516 \\
\end{array}$ & 532 & 532 & 534 \\
\hline
\end{tabular}


ме того, исходя из значений частот симметричных колебаний $v_{s(\text { (S) }}$, можно утверждать, что тиосульфат-ион связан с катионом металла через атом кислорода. Таким образом, при образовании смешанных ТТКС тиосульфат-ион координируется бидентатно через серу и кислород.

Следует отметить, что в ИК спектре ТТКС свинца наблюдается незначительное смещение максимума поглощения $v_{s(\text { so) }}$ в высокочастотную область по сравнению с частотами $\mathrm{PbS}_{2} \mathrm{O}_{3}$ (табл. 2). По всей видимости, это обусловлено упрочнением связи $\mathrm{Pb}-\mathrm{S}$. В этом случае частота валентных колебаний связи S-S тиосульфатиона должна понижаться, но это сложно отметить, так как полоса $v_{\mathrm{SS}}$ перекрывается с полосами $\delta_{\text {NCN }}, \delta_{\text {NCS }}$ молекулы тиомочевины. Присутствие в ИК спектре ТТКС свинца полос поглощения $v_{\mathrm{OH}}$ в диапазоне частот $3405-3490 \mathrm{~cm}^{-1}$ говорит о вхождении воды во внутреннюю сферу образующегося комплекса.

Анализ полученных данных позволяет говорить, что при взаимодействии нитрата свинца с тиомочевиной и тиосульфатом натрия в молярных соотношениях компонентов $1: 2: 2,1: 2: 3$ и $1: 2: 4$ образуется комплекс состава $\left[\mathrm{Pb}\left(\mathrm{SCN}_{2} \mathrm{H}_{4}\right)\left(b i-\mathrm{S}_{2} \mathrm{O}_{3}\right)\left(\mathrm{H}_{2} \mathrm{O}\right)\right]$. В водных растворах $\mathrm{Cd}\left(\mathrm{NO}_{3}\right)_{2}-\mathrm{Na}_{2} \mathrm{~S}_{2} \mathrm{O}_{3}-\mathrm{SCN}_{2} \mathrm{H}_{4}$ при рассматриваемых концентрациях компонентов наиболее вероятно образование комплекса $\left[\mathrm{Cd}\left(\mathrm{SCN}_{2} \mathrm{H}_{4}\right)_{2}\left(b i-\mathrm{S}_{2} \mathrm{O}_{3}\right)\right]$.

Результаты рентгенофазового анализа показали, что при термодеструкции тиосульфатнотиомочевинных комплексов кадмия формируются пленки CdS гексагональной (вюрцитной, w) модификации независимо от молярного соотношения исходных компонентов. На дифрактограммах синтезированных образцов зарегис- трированы рефлексы 002, 102 и 103, относящиеся к вюртцитной модификации (табл. 3). Ожидаемая фаза оксида кадмия, которая могла бы сформироваться из-за существования в ТТКС связей «кадмий-кислород», в пленках CdS не обнаружена.

При распылении растворов с разными молярными соотношениями компонентов $\mathrm{Pb}\left(\mathrm{NO}_{3}\right)_{2}$, $\mathrm{Na}_{2} \mathrm{~S}_{2} \mathrm{O}_{3}$ и $\mathrm{SCN}_{2} \mathrm{H}_{4}$ происходит осаждение пленок $\mathrm{PbS}$ кубической структуры (табл. 4). На дифрактограммах синтезированных образцов наиболее интенсивными являются дифракционные пики, относящиеся к отражениям 111, 200, 220.

Для изучения оптических свойств синтезированных образцов были построены степенные зависимости оптической плотности от энергии фотона в координатах $(h v D)^{2}=f(h v)$ (рис. 1,2$)$, содержащие в области края собственного поглощения линейный участок, экстраполяцией которого до оси абсцисс была определена ширина запрещенной зоны $[10,11]$. Для всех исследуемых пленок CdS ширина запрещенной зоны имеет значения $2.4 \pm 0.01 \mathrm{eV}$ (табл. 5), что характерно для вюртцитной модификации сульфида (по данным [16] $E_{g}=2.4 \mathrm{eV}$ ). Таким образом, изменение концентрации компонентов в распыляемом растворе не влияет на оптическую ширину запрещенной зоны сульфида кадмия. Нужно отметить, что при распылении растворов комплексов $\left[\mathrm{Cd}\left(\mathrm{SCN}_{2} \mathrm{H}_{4}\right)_{4}\right]\left(\mathrm{NO}_{3}\right)_{2}$, образующихся при взаимодействии нитрата кадмия и тиомочевины, происходит осаждение пленок CdS также преимущественно вюртцитной структуры с несколько меньшей шириной запрещенной зоны $2.36 \mathrm{eV}$, что может быть связано с растворением в пленке кислорода при частичном ее окислении.

Табл. 3. Межплоскостные расстояния в пленках сульфида кадмия

[Table 3. Interplanar distances in the cadmium sulfide films]

\begin{tabular}{|c|c|c|c|c|c|c|}
\hline \multirow{2}{*}{\multicolumn{3}{|c|}{$\begin{array}{l}\text { По данным для } w \text {-CdS [9] } \\
\text { [Reference data for } w \text {-CdS [9]] }\end{array}$}} & \multicolumn{4}{|c|}{$\begin{array}{c}\text { Молярное соотношение компонентов } \\
\mathrm{Cd}\left(\mathrm{NO}_{3}\right)_{2}-\mathrm{SCN}_{2} \mathrm{H}_{4}-\mathrm{Na}_{2} \mathrm{~S}_{2} \mathrm{O}_{3} \\
{[\mathrm{Molar} \text { ratio of components }} \\
\left.\mathrm{Cd}\left(\mathrm{NO}_{3}\right)_{2}-\mathrm{SCN}_{2} \mathrm{H}_{4}-\mathrm{Na}_{2} \mathrm{~S}_{2} \mathrm{O}_{3}\right]\end{array}$} \\
\hline & & & \multicolumn{2}{|c|}{$1: 2: 3$} & \multicolumn{2}{|c|}{$1: 2: 4$} \\
\hline$h k l$ & $d, \mathrm{нм}$ & $I, \%$ & $d, \mathrm{HM}$ & $I, \%$ & $d, \mathrm{HM}$ & $I, \%$ \\
\hline 002 & 0.335 & 48.0 & 0.331 & 86.7 & 0.329 & 100 \\
\hline 102 & 0.245 & 24.0 & 0.242 & 100 & 0.243 & 46.8 \\
\hline 103 & 0.189 & 100.0 & 0.191 & 15.8 & 0.193 & 11.3 \\
\hline
\end{tabular}

Обозначения: $d$ - межплоскостное расстояние; $I$ - интенсивность рефлекса.

[Designation: $d$ - interplanar distance; $I$ - diffraction peak intensity.] 
Табл. 4. Межплоскостные расстояния в пленках сульфида свинца

[Table 4. Interplanar distances in the lead sulfide films]

\begin{tabular}{|c|c|c|c|c|c|c|c|c|}
\hline \multirow{2}{*}{\multicolumn{3}{|c|}{$\begin{array}{c}\text { По данным для PbS [9] } \\
\text { [Reference data for PbS [9]] }\end{array}$}} & \multicolumn{6}{|c|}{$\begin{array}{c}\text { Молярное соотношение компонентов } \\
\mathrm{Pb}\left(\mathrm{NO}_{3}\right)_{2}-\mathrm{SCN}_{2} \mathrm{H}_{4}-\mathrm{Na}_{2} \mathrm{~S}_{2} \mathrm{O}_{3} \\
{\left[\mathrm{Molar}_{2} \text { ratio of components }\right.} \\
\left.\mathrm{Pb}\left(\mathrm{NO}_{3}\right)_{2}-\mathrm{SCN}_{2} \mathrm{H}_{4}-\mathrm{Na}_{2} \mathrm{~S}_{2} \mathrm{O}_{3}\right]\end{array}$} \\
\hline & & & \multicolumn{2}{|c|}{$1: 2: 2$} & \multicolumn{2}{|c|}{$1: 2: 3$} & \multicolumn{2}{|c|}{$1: 2: 4$} \\
\hline hkl & $d, \mathrm{~nm}$ & $I, \%$ & $d, \mathrm{~nm}$ & $I, \%$ & $d, \mathrm{~nm}$ & $I, \%$ & $d, \mathrm{~nm}$ & $I, \%$ \\
\hline 111 & 0.342 & 95 & 0.342 & 64.3 & 0.343 & 100 & 0.342 & 97.4 \\
\hline 200 & 0.296 & 100 & 0.297 & 100 & 0.297 & 99.6 & 0.296 & 100 \\
\hline 220 & 0.209 & 64 & 0.208 & 37.8 & 0.209 & 48.2 & 0.209 & 60.1 \\
\hline 311 & 0.178 & 37 & 0.179 & 20.3 & 0.178 & 28.6 & 0.179 & 34.1 \\
\hline 222 & 0.171 & 20 & 0.168 & 15.2 & 0.170 & 11.8 & 0.171 & 18.8 \\
\hline 400 & 0.148 & 10 & - & - & - & - & 0.148 & 8.0 \\
\hline 331 & 0.136 & 13 & - & - & - & - & 0.135 & 11.2 \\
\hline 420 & 0.133 & 21 & - & - & 0.133 & 19.6 & 0.132 & 17.0 \\
\hline
\end{tabular}

Обозначения: $d$ - межплоскостное расстояние; $I$ - интенсивность рефлекса.

[Designation: $d$ - interplanar distance; $I$ - diffraction peak intensity.]

Табл. 5. Оптическая ширина запрещенной зоны $\left(E_{g}\right)$ пленок $\mathrm{CdS}$ и $\mathrm{PbS}$, полученных при различных соотношениях компонентов в исходном растворе

[Table 5. Optical band gap $\left(E_{g}\right)$ of CdS and $\mathrm{PbS}$ films prepared at different ratios of components in the initial solution]

\begin{tabular}{|c|c|c|}
\hline \multirow{2}{*}{$\begin{array}{c}\text { Молярное соотношение } \\
\text { компонентов } \\
\mathrm{M}\left(\mathrm{NO}_{3}\right)_{2}-\mathrm{SCN}_{2} \mathrm{H}_{4}-\mathrm{Na}_{2} \mathrm{~S}_{2} \mathrm{O}_{3} \\
{[\mathrm{Molar} \text { ratio of components }} \\
\left.\mathrm{M}\left(\mathrm{NO}_{3}\right)_{2}-\mathrm{SCN}_{2} \mathrm{H}_{4}-\mathrm{Na}_{2} \mathrm{~S}_{2} \mathrm{O}_{3}\right]\end{array}$} & \multicolumn{2}{|c|}{$\begin{array}{c}E_{\mathrm{g}}, \ni \mathrm{B} \\
{\left[E_{\mathrm{g}}^{\mathrm{g}}, \mathrm{eV}\right]} \\
\end{array}$} \\
\hline & $\mathrm{CdS}$ & $\mathrm{PbS}$ \\
\hline $1: 2: 2$ & 2.40 & 0.56 \\
\hline $1: 2: 3$ & 2.39 & 0.54 \\
\hline $1: 2: 4$ & 2.41 & 0.50 \\
\hline
\end{tabular}

Исследование оптических свойств пленок $\mathrm{PbS}$ показало, что с увеличением содержания в исходном растворе тиосульфата натрия оптическая ширина запрещенной зоны образцов уменьшается от 0.56 до $0.50 \mathrm{eV}$ (табл. 5). При соотношении компонентов 1:2:4 формируются пленки сульфида свинца, характеризующиеся наименьшим по сравнению с другими образцами значением $E_{g}=0.50 \mathrm{eV}$, что наиболее близко к справочным данным (0.42 eV [17]). Такая особенность изменения $E_{\mathrm{g}}$ связана с увеличением концентрации серосодержащих лигандов в исходном растворе, что способствует формированию пленок $\mathrm{PbS}$ с менее дефектной структурой и составом, близким к стехиометрическому. В целом значения оптической ширины запрещенной зоны пле- нок $\mathrm{PbS}$, осажденных из растворов TTKC (0.5$0.56 \mathrm{eV})$, несколько выше таковых значений для слоев сульфида свинца, полученных авторами [18] при той же температуре из координационного соединения $\left[\mathrm{Pb}\left(\mathrm{SCN}_{2} \mathrm{H}_{4}\right)_{2}\left(\mathrm{CH}_{3} \mathrm{COO}\right)_{2}\right](0.45 \mathrm{eV})$.

\section{ЗАКЛЮЧЕНИЕ}

Установлено, что в водных растворах, содержащих нитрат кадмия, тиосульфат натрия и тиомочевину с варьируемыми молярными соотношениями компонентов, происходит образование нейтральных координационных соединений $\left[\mathrm{Cd}\left(\mathrm{SCN}_{2} \mathrm{H}_{4}\right)_{2}\left(b i-\mathrm{S}_{2} \mathrm{O}_{3}\right)\right]$ с бидентатным $\mathrm{S}, \mathrm{O}$-координированным тиосульфат-ионом. В растворах $\mathrm{Pb}\left(\mathrm{NO}_{3}\right)_{2}$, содержащих тиосульфат натрия и тиомочевину, формируются нейтральные координационные соединения $\left[\mathrm{Pb}\left(\mathrm{SCN}_{2} \mathrm{H}_{4}\right)\left(b i-\mathrm{S}_{2} \mathrm{O}_{3}\right)\left(\mathrm{H}_{2} \mathrm{O}\right)\right]$. Выявлено, что в то время как ТТКС кадмия и свинца тиосульфат-ион координируется к катиону металла одновременно через атомы серы и кислорода, тиомочевина координируется монодентатно через атом серы.

Показана возможность осаждения пленок сульфидов кадмия и свинца методом пиролиза аэрозоля растворов тиосульфатно-тиомочевинных координационных соединений. Установлено, что из растворов ТТКС при температуре $400{ }^{\circ} \mathrm{C}$ формируются пленки CdS в структуре вюртцита, обладающие оптической шириной запрещенной зоны $2.4 \mathrm{eV}$. Слои сульфида свинца, полученные при той же температуре, имеют кубическую структуру и ширину запрещенной 


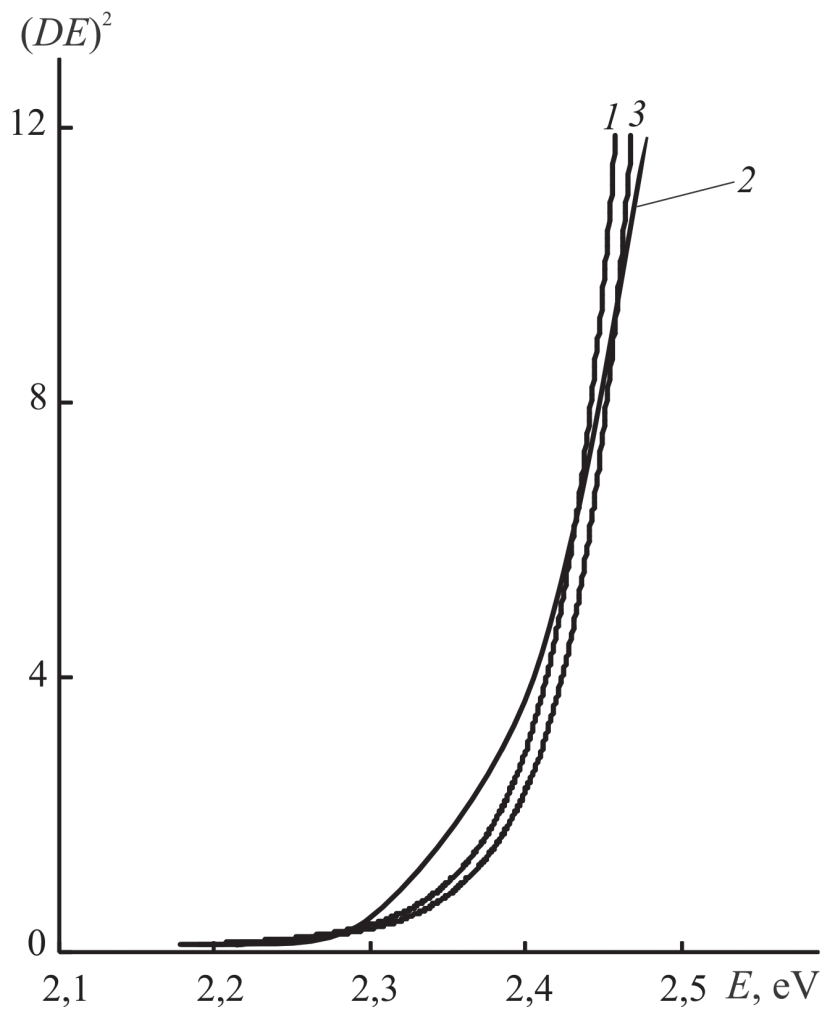

Рис. 1. Спектры поглощения в области края фундаментального поглощения пленок CdS, полученных при молярных соотношениях $\mathrm{Cd}\left(\mathrm{NO}_{3}\right)_{2}, \mathrm{SCN}_{2} \mathrm{H}_{4}$ и $\mathrm{Na}_{2} \mathrm{~S}_{2} \mathrm{O}_{3} 1: 2: 2(1), 1: 2: 3$ (2) и 1:2:4 (3)

[Fig. 1. Power-law dependencies of the coefficient on the photon energy for the films prepared at different molar ratio $\mathrm{Cd}\left(\mathrm{NO}_{3}\right)_{2}, \mathrm{SCN}_{2} \mathrm{H}_{4}$ and $\mathrm{Na}_{2} \mathrm{~S}_{2} \mathrm{O}_{3}$ $1: 2: 2(1), 1: 2: 3(2)$ и $1: 2: 4$ (3)]

зоны 0.50-0.56 eV. Тип кристаллической структуры синтезированных сульфидов и оптическая ширина запрещенной зоны пленок сульфида кадмия не зависят от соотношения компонентов в исходном растворе, однако пленок сульфида свинца наблюдается некоторое уменьшение ширины запрещенной зоны с ростом содержания тиосульфата натрия в исходном растворе.

\section{ИСТОЧНИК ФИНАНСИРОВАНИЯ}

Работа выполнена при финансовой поддержке РФФИ, проект № 18-33-01215 мол_а.

\section{БЛАГОДАРНОСТИ}

Исследования проведены с использованием оборудования Центра коллективного пользования Воронежского государственного университета. URL: http://ckp.vsu.ru.

\section{КОНФЛИКТ ИНТЕРЕСОВ}

Авторы декларируют отсутствие явных и потенциальных конфликтов интересов, связанных с публикацией настоящей статьи.

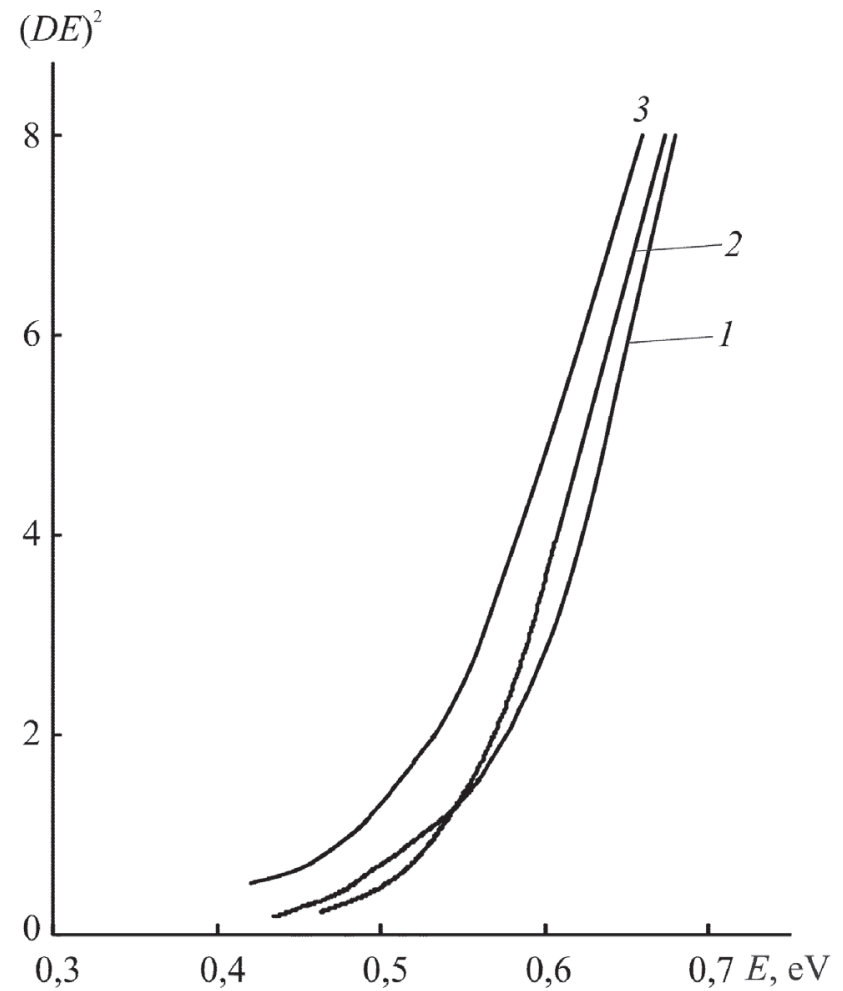

Рис. 2. Спектры поглощения в области края фундаментального поглощения пленок PbS, полученных при молярных соотношениях $\mathrm{Pb}\left(\mathrm{NO}_{3}\right)_{2}, \mathrm{SCN} 2 \mathrm{H} 4$ и $\mathrm{Na}_{2} \mathrm{~S}_{2} \mathrm{O}_{3} 1: 2: 2(1), 1: 2: 3$ (2) и $1: 2: 4$ (3)

[Fig. 2. Power-law dependencies of the coefficient on the photon energy for the films prepared at different molar ratio $\mathrm{Pb}\left(\mathrm{NO}_{3}\right)_{2}, \mathrm{SCN}_{2} \mathrm{H}_{4}$ and $\mathrm{Na}_{2} \mathrm{~S}_{2} \mathrm{O}_{3}$ $1: 2: 2(1), 1: 2: 3$ (2) и $1: 2: 4(3)]$

\section{СПИСОК ЛИТЕРАТУРЫ}

1. Семенов В. Н., Наумов А. В. Процессы направленного синтеза пленок сульфидов металлов из тиокарбамидных координационных соединений // Вестник ВГУ. Серия химия, биология, 2000, № 2, c. 50-55. URL: http://www.vestnik.vsu.ru/pdf/ chembio/2000/02/semenov.pdf

2. Семенов В. Н., Наумов А. В. Термическое разложение тиомочевинных координационных соединений кадмия // Журнал общей химии, 2001, т. 71(4), с. 533-537.

3. Тухтаев Р. К., Болдырев, В. В., Гаврилов А. И., Ларионов С. В., Мячина Л. И., Савельева З. А. Синтез сульфидов металлов из серосодержащих комплексных соединений методом самораспространяющегося горения // Неорганические материалы, 2002, т. 38(10), с. 1173-1180.

4. Марков В.Ф., Маскаева Л. Н., Иванов П. Н. Гидрохимическое осаждение пленок сульфидов металлов: моделирование и эксперимент. Екатеринбург: Изд-во УрО РАН, 2006, 217 с.

5. Семенов В. Н., Власенко Н. В. Процессы комплексообразования в системах тиомочевина - кад- 
миевая соль кислородсодержащей кислоты // Журнал неорганической химии, 1992, т. 37(4), с. 929-933.

6. Угай Я.А., Семенов В.Н.. Авербах Е.M., Шамшеева И.Л. Исследование взаимодействия солей кадмия с тиомочевиной при получении пленок сульфида кадмия // Журнал прикладной химии, 1988, т. 61(11), с. 2409-2414.

7. Егоров Н. Б., Еремин Л. П., Ларионов А. М., Усов В.Ф. Превращение тиосульфато-тиомочевинных комплексов свинца при нагревании // Известия Томского политехнического университета, 2010, т. 317(3), с. 99-102.

8. Егоров Н. Б., Еремин Л. П., Усов В. Ф., Ларионов А. М, Фитерер И. П. Исследование тиосульфатотиомочевинных комплексов свинца // Журнал неорганической химии, 2008, т. 53(1), с. 123-128.

9. Powder Diffraction File. Swarthmore: Joint Committee on Powder Diffraction Standards, 1996.

10. Уханов Ю. И. Оптические свойства полупроводников. М.: Наука, 1977, 367 с.

11. Равич Ю. И., Ефимова Б. А., Смирнов И. А. Методы исследования полупроводников в применении к халькогенидам свинца PbTe, PbSe, PbS. M.: Наука, 1968, 384 с.
12. Харитонов Ю. Я., Брега В. Д., Аблов А. В. // Журнал неорганической химии, 1971, т. 16(2), с. 572573.

13. Харитонов Ю. Я., Брега В. Д., Аблов А. В., Проскина Н.Н.// Журнал неорганической химии, 1974, т. 19(8), c. 2166-2177.

14. Freedman A. N., Straughan B. P. Vibrational spectra and structures of some thiosulphate complexes // Spectrochim. Acta, 1971,v. 27A, pp. 1455-1465. DOI: 10.1016/0584-8539(71)80095-8

15. Накамото К. ИК-спектры и спектры КР неорганических и координационных соединений. М.: Мир, 1991, 536 с.

16. Бабичев А. П., Бабушкина Н. А., Братковский А.М. Физические величины: Справочник, Москва, Энергоатомиздат, 1991, 1231 с.

17. Самсонов В. Г., Дроздова С. В. Сульфиды, М.: Металлургия, 1972, с. 50-55.

18. Карнушина В.А., Семенов В. Н., Лукин А. Н., Овечкина Н. М., Никитин Л. М. Свойства пленок сульфида свинца, осажденных из координационного соединения $\left[\mathrm{Pb}\left(\mathrm{N}_{2} \mathrm{H}_{4} \mathrm{CS}\right)_{2}\left(\mathrm{CH}_{3} \mathrm{COO}\right)_{2}\right]$. // Конденсированные среды и межфазные границы, 2017, T. 19(2), с. 215-221. DOI: 10.17308/KCMF.2017. $19 / 194$

UDC 546.221:539.232:538.9

DOI: https://doi.org/10.17308/kcmf.2019.21/762

Received 19.03.2019

Accepted 15.05.2019

\title{
THE DEPOSITION OF LAYERS OF SULFIDES OF CADMIUM AND LEAD FROM THIOSULFATE-TIOUREA COMPLEXES AND THEIR PROPERTIES
}

\author{
(c) 2019 V. N. Semenov ${ }^{1}$, T. V. Samofalova ${ }^{1 \bowtie}$, A. V. Naumov ${ }^{1}$, N. M. Ovechkina ${ }^{2}$ \\ ${ }^{1}$ Voronezh State University \\ 1, Universitetskaya pl., 394018 Voronezh, Russian Federation \\ ${ }^{2}$ Voronezh State Medical University named N.N. Burdenko \\ 10 Studencheskaya str., 394036 Voronezh, Russian Federation
}

\begin{abstract}
Objective. The results of studies of cadmium and lead sulfide films deposited from aqueous solutions of thiourea-thiosulfate complexes by aerosol pyrolysis at a temperature of $400{ }^{\circ} \mathrm{C}$ are presented. The study of thiourea-thiosulfate coordination compounds (TTCC) by infrared spectroscopy was carried out.

Results. It was found that in aqueous solutions containing cadmium nitrate, sodium thiosulfate and thiourea with different molar ratios of components the coordination compounds $\left[\mathrm{Cd}\left(\mathrm{SCN}_{2} \mathrm{H}_{4}\right)_{2}\left(\right.\right.$ bi- $\left.\left.\mathrm{S}_{2} \mathrm{O}_{3}\right)\right]$ are formed. It was revealed that $\left[\mathrm{Pb}\left(\mathrm{SCN}_{2} \mathrm{H}_{4}\right)\left(\right.\right.$ bi- $\left.\left.\mathrm{S}_{2} \mathrm{O}_{3}\right)\left(\mathrm{H}_{2} \mathrm{O}\right)\right]$ complexes are formed in the $\mathrm{Pb}\left(\mathrm{NO}_{3}\right)_{2}-\mathrm{Na}_{2} \mathrm{~S}_{2} \mathrm{O}_{3}-\mathrm{SCN}_{2} \mathrm{H}_{4}-\mathrm{H}_{2} \mathrm{O}$ system. It has been established that at the formation of mixed TTCC of lead, as well as cadmium, monodentate coordination of thiourea to the metal cation through the sulfur atom carried out, and the thiosulfate ion is coordinated
\end{abstract}

$\triangle$ Samofalova Tatyana Vladimirovna, e-mail: TSamofalova@bk.ru 
bidentately through sulfur and oxygen. The crystal structure and phase composition of sulfides were studied by X-Ray phase analysis.

Conclusion. It is established that independently of the molar ratio of components in the initial solution the cadmium sulfide films crystallize in the structure of wurtzite, and lead sulfide films - in cubic modification. The transmission spectra of synthesized CdS and PbS films in the region of the fundamental absorption edge were investigated by optical spectrometry. It was revealed that the optical band gap of the cadmium sulfide films is $2.4 \pm 0.01 \mathrm{eV}$. The films of lead sulfide are characterized by a slight decrease of the band gap with an increase of the sodium thiosulfate content in the initial solution from 0.56 to $0.50 \mathrm{eV}$.

Keywords: thiourea coordination compounds, thiourea-thiosulfate complexes, aerosol pyrolysis, cadmium sulfide, lead sulfide, films.

\section{SOURCE OF FINANCING}

The study was supported by the Russian Foundation for Basic Research (grant No. № 1833-01215 mol_a).

\section{ACKNOWLEDGMENTS}

The research results were obtained using the equipment of the Center for Collective Use of Equipment Voronezh State University. URL: http:// ckp.vsu.ru.

\section{CONFLICT OF INTEREST}

The authors declare the absence of obvious and potential conflicts of interest related to the publication of this article.

\section{REFERENCES}

1. Semenov V. N., Naumov A. V. Protsessy napravlennogo sinteza plenok sul'fidov metallov iz tiokarbamidnykh koordinatsionnykh soedineniy [Processes of the directed synthesis of metal sulfide films from thiocarbamide coordination compounds]. Proceedings of Voronezh State University. Series: Chemistry. Biology. Pharmacy, 2000, no. 2, pp. 50-55. (in Russ.)

2. Semenov V. N., Naumov A. V. Thermal decomposition of cadmium thiourea coordination compounds. Russian Journal of General Chemistry, 2001, v. 71(4), pp. 495-499. DOI: 10.1023/A:101230 6512566

3. Tuhtaev R. K., Boldyrev V. V., Gavrilov A. I., Larionov S. V., Mjachina L. I., Savel'eva Z. A. Sintez sul'fidov metallov iz serosoderzhashchikh kompleksnykh soedineniy metodom samorasprostranyayushchegosya goreniya [Synthesis of metal sulfides from sulfur-containing complex compounds by self-propagating combustion]. Inorganic Materials, 2002, v. 38(10), pp. 1173-1180. (in Russ.)

4. Markov V. F., Maskaeva L. N., Ivanov P. N. Gidrohimicheskoe osazhdenie plenok sul'fidov metallov: modelirovanie i jeksperiment [Hydrochemical deposition of metal sulfide films: modeling and experiment]. Ekaterinburg, Ural Branch of the Russian Academy of Sciences Publ., 2006, 217 p. (in Russ.)
5. Semenov V. N., Vlasenko N.V. Protsessy kompleksoobrazovaniya v sistemakh tiomochevina - kadmievaya sol' kislorodsoderzhashchey kisloty [Complexation processes in the systems of thiourea - cadmium salt of oxygen-containing acid]. Russian Journal of Inorganic Chemistry, 1992, v. 37(4), pp. 929-933. (in Russ.)

6. Ugaj Ja. A., Semenov V. N., Averbah E. M., Shamsheeva I. L. Issledovanie vzaimodeystviya soley kadmiya s tiomochevinnoy pri poluchenii plenok sul'fida kadmiya [Investigation of the interaction of cadmium salts with thiourea in the preparation of cadmium sulfide films]. Journal of Applied Chemistry of the USSR, 1988, v. 61(11), pp. 2409-2414. (in Russ.)

7. Egorov N. B., Eremin L. P., Larionov A. M., Usov V.F. Prevrashchenie tiosul'fato-tiomochevinnykh kompleksov svintsa pri nagrevanii [The transformation of thiosulfate-thiourea lead complexes when heated]. Izvestija Tomskogo politehnicheskogo universiteta, 2010, v. 317(3), pp. 99-102. (in Russ.)

8. Egorov N. B., Usov V. F., Fiterer I. P., Eremin L. P., Larionov A.M. Thiosulfatothiourea lead complexes. Russian Journal of Inorganic Chemistry, 2008, v. 53(1), pp. 117-122. DOI: 10.1134/S0036023608010166

9. Powder Diffraction File. Swarthmore: Joint Committee on Powder Diffraction Stan-dards, 1996.

10. Uhanov Ju. I. Opticheskie svojstva poluprovodnikov [Optical properties of semiconductors], Moscow, Nauka Publ., 1977, 367 p. (in Russ.)

11. Ravich Ju. I., Efimova B. A., Smirnov I. A. Metody issledovanija poluprovodnikov $v$ primenenii $k$ hal'kogenidam svinca PbTe, $\mathrm{PbSe}, \mathrm{PbS}$ [Methods of semiconductor research as applied to lead chalcogenides PbTe, PbSe, PbS]. Moscow, Nauka Publ., 1968, 384 p. (in Russ.)

12. Haritonov Ju. Ja., Brega V. D., Ablov A. V. Russian Journal of Inorganic Chemistry, 1971, v. 16(2), pp. 572-573. (in Russ.)

13. Haritonov Ju. Ja., Brega V. D., Ablov A. V., Proskina N. N. Russian Journal of Inorganic Chemistry,1974, v. 19(8), pp. 2166-2177. (in Russ.)

14. Freedman A. N., Straughan B. P. Vibrational spectra and structures of some thiosulphate complexes. Spectrochim. Acta, 1971, v. 27A, pp. 1455-1465. DOI: $10.1016 / 0584-8539(71) 80095-8$ 
15. Nakamoto K. Infrared and Raman spectra of inorganic and coordination compounds. 4th ed. John Wiley \& Sons, 1986. 245 p.

16. Babichev A. P., Babushkina N. A., Bratkovskij A. M. Fizicheskie velichiny: Spravochnik [Physical quantities: Handbook]. Moscow, Jenergoatomizdat Publ., 1991, 1231 p. (in Russ.)

17. Samsonov V. G., Drozdova S. V. Sul'fidy [Sulphides]. Moscow, Metallurgiya Publ., 1972, pp. 50-55. (in Russ.)
18. Karnushina V. A., Semenov V. N., Lukin A. N., Ovechkina N. M., Nikitin L. M. Properties of led sulfide films deposed from a coordination $\left[\mathrm{Pb}\left(\mathrm{N}_{2} \mathrm{H}_{4} \mathrm{CS}\right)_{2}\left(\mathrm{CH}_{3} \mathrm{COO}\right)_{2}\right]$. Condensed matter and interphases , 2017, v. 19(2), pp. 215-221. DOI: 10.17308/ kcmf.2017.19/194 (in Russ.)
Семенов Виктор Николаевич - д. х. н., профессор, заведующий кафедрой общей и неорганической химии, Воронежский государственный университет, Воронеж, Российская Федерация; e-mail: office@chem.vsu.ru. ORCID iD 00000002-4247-5667.

Самофалова Татьяна Владимировна - к. х. н., ассистент кафедры общей и неорганической химии, Воронежский государственный университет, Воронеж, Российская Федерация, e-mail: TSamofalova@bk.ru. ORCID iD 0000-0002-42774536.

Наумов Александр Владимирович - к. х. н., доцент кафедры общей и неорганической химии, Воронежский государственный университет, Воронеж, Российская Федерация; e-mail: aither@ bk.ru. ORCID iD 0000-0002-1313-8573.

Овечкина Надежда Митрофановна - ассистент кафедры химии, Воронежский государственный медицинский университет им. Н. Н. Бурденко, Воронеж, Российская Федерация; e-mail: nadezhda.ovechkina@rambler.ru.
Semenov Victor N. - Dr. Sci. (Chem.), Full Professor, Head of the Department of General and Inorganic Chemistry, Voronezh State University, Voronezh, Russian Federation; e-mail: semenov@chem. vsu.ru. ORCID iD 0000-0002-4247-5667.

Samofalova Tatyana V. - Cand. Sci. (Chem.), Assistant of the Department of General and Inorganic Chemistry, Voronezh State University, Voronezh, Russian Federation; e-mail: TSamofalova@bk.ru. ORCID iD 0000-0002-4277-4536.

Naumov Aleksandr V. - Cand. Sci. (Chem.), Associate Professor of the Department of General and Inorganic Chemistry, Voronezh State University, Voronezh, Russian Federation; e-mail: aither@bk.ru. ORCID iD 0000-0002-1313-8573.

Ovechkina Nadezhda M. - Assistant of the Department of Chemistry, Voronezh State Medical University N.N. Burdenko, Voronezh, Russian Federation; e-mail: nadezhda.ovechkina@rambler.ru. 